Received: 2013.03.23

Accepted: 2013.05.19

Published: 2013.06.26
Authors' Contribution: Study Design A Data Collection B Statistical Analysis C Data Interpretation D Manuscript Preparation E Literature Search F Funds Collection G

\section{Ambulatory blood pressure monitoring can unmask hypertension in patients with psoriasis vulgaris}

\author{
ABCDEF 1 Ahmet Bacaksiz \\ ABCDE 1 Ercan Erdogan \\ $A B C$ Osman Sonmez \\ $A B C D 1$ Emrah Sevgili \\ DEF 1 Abdurrahman Tasal \\ AD 2 Nahide Onsun \\ BD 2 Bugce Topukcu \\ BD 1 Beytullah Kulaç \\ CD 3 Omer Uysal \\ EF 1 Omer Goktekin
}

1 Department of Cardiology, Bezmiâlem Foundation University, Istanbul, Turkey 2 Department of Dermatology, Bezmiâlem Foundation University, Istanbul, Turkey 3 Department of Biostatistics and Medical Informatics, Bezmiâlem Foundation University, Istanbul, Turkey
Corresponding Author: Source of support:
Ahmet Bacaksiz, e-mail: ahmetbacaxiz@gmail.com Departmental sources

Background: Psoriasis vulgaris is one of the most prevalent chronic, inflammatory skin disorders. Patients with psoriasis have excess risk of essential hypertension. Masked hypertension $(\mathrm{MH})$, defined as normal office blood pressure (BP) with elevated ambulatory BP (ABPM), has been drawing attention recently due to its association with increased risk of developing sustained hypertension, cardiovascular morbidity, and mortality. The aim of this study was to investigate the prevalence of $\mathrm{MH}$ in psoriatic patients.

Material/Methods: On hundred and ten middle-aged, normotensive, non-obese patients with psoriasis vulgaris and 110 age- and sex-matched normotensive controls were included in the study. ABPM was performed in all participants over a 24-h period. The clinical severity of the disease was determined according to current indexes.

Results: The prevalence of $\mathrm{MH}$ among subjects with psoriasis vulgaris was $31.8 \%$ and increased compared to control subjects $(p<0.01)$. Predictors of $\mathrm{MH}$ in patients with psoriasis vulgaris were detected as male sex, smoking, obesity-related anthropometric measures, and disease activity. Male sex, waist circumference, and diffuse psoriatic involvement were detected as independent predictors of $\mathrm{MH}$.

Conclusions: $\quad \mathrm{MH}$ is prevalent in patients with psoriasis vulgaris. Assessment with ABPM and close follow-up for development of hypertension is reasonable.

Key words: $\quad$ psoriasis $\bullet$ masked hypertension • blood pressure monitoring, ambulatory $\bullet$ hypertension cardiovascular risk

Full-text PDF: http://www.medscimonit.com/download/index/idArt/889197

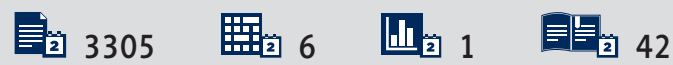




\section{Background}

Psoriasis vulgaris is one of the most prevalent chronic, multisystemic, inflammatory skin disorders. It is characterized by formation of inflamed plaques in the skin, scalp, nails, and joints $[1,2]$. It affects nearly $3 \%$ of the global population, including 125 million people worldwide [3]. Although the pathogenesis of psoriasis is still not fully understood, increased oxidative stress, endothelial dysfunction, and systemic inflammatory response are considered as the most important mechanisms in the development of the disease, as is the case in most cardiovascular diseases [4]. Patients with psoriasis have excess risk of atherosclerotic vasculopathies such as coronary artery disease, hypertension, metabolic syndrome, obesity, and diabetes mellitus [5-7]. It has been clearly demonstrated that arterial hypertension is common in patients with psoriasis vulgaris, with a prevalence of $8.9 \%$ to $44.4 \%$ [8-10]. Although hypertension risk was found to be correlated with severity of psoriasis, hypertension was even more frequent in patients with mild disease compared to normal individuals when other variables like age, smoking, alcohol consumption, body mass index (BMI), and physical activity had taken into account [10].

Masked hypertension $(\mathrm{MH})$ is a clinical entity defined in subjects who have normal office blood pressure (BP) $(<140 / 90$ $\mathrm{mmHg}$ ) but elevated ambulatory or home BP (daytime systolic BP >135 mmHg or daytime diastolic BP >85 $\mathrm{mmHg}$ ) [11]. It is closely associated with development of sustained hypertension, cardiovascular morbidity, and mortality [12-14]. The prevalence of $\mathrm{MH}$ in the general population was estimated at $8 \%$ but it increased to $49 \%$ in specific study groups [15-19]. Some of the factors leading to $\mathrm{MH}$ have defined as older age, male sex, smoking, contraceptive use in women, and sedentary lifestyle [20]. The percentage of masked hypertensives among patients with psoriasis is not clear. The adverse cardiovascular outcome of these patients could be related to a higher percentage of $\mathrm{MH}$. The aim of the present study was to determine the prevalence of $\mathrm{MH}$ in subjects with psoriasis vulgaris as evaluated by 24-h ambulatory BP monitoring (ABPM) device. Additionally, clinical variables and laboratory findings associated with $\mathrm{MH}$ were investigated.

\section{Material and Methods}

\section{Study design}

The study was carried out at the Dermatology and Cardiology clinics of Bezmiâlem Foundation University Hospital, Istanbul, Turkey. A cross-sectional study design was used to compare the prevalence of $\mathrm{MH}$ in patients $18-45$ years old with psoriasis vulgaris and controls. The patient group consisted of eligible patients selected from consecutive patients with psoriasis vulgaris admitted to the outpatient clinic of the Dermatology Department (Group 1). Also, age-, sex-, and BMI-matched subjects with normal office BP from the Cardiology Department outpatient clinic were used as the control group (Group 2). Control subjects were selected from subjects who were admitted to the hospital for symptoms suggesting high BP such as headaches and dizziness with normal office BP. This study was approved by the Bezmiâlem Foundation University, School of Medicine Ethics Committee and was conducted in accordance with the ethics principles described by the Declaration of Helsinki. Written informed consent was obtained from all participants.

\section{Study population}

Patients who had past or concurrent diseases such as essential hypertension (office BP $\geq 140 / 90 \mathrm{mmHg}$ and/or average 24-h ambulatory $\mathrm{BP} \geq 135 / 85 \mathrm{mmHg}$ ), diabetes mellitus, dyslipidemia (a total cholesterol level $>240 \mathrm{mg} / \mathrm{dl}$ or taking lipidlowering agents), obesity (BMI $\left.\geq 30 \mathrm{~kg} / \mathrm{m}^{2}\right)$, coronary artery disease, liver or kidney diseases, collagen vascular diseases, any cardiovascular drug use, or abnormal thyroid function were excluded from the study. None of the patients had a history of a respiratory disease such as asthma, chronic obstructive pulmonary disease, emphysema, or chronic bronchitis. Also, participants with current or previous (within the last 6 months) use of oral contraceptives, hormone replacement therapy, glucocorticoids, non-steroidal anti-inflammatory drugs, methotrexate, hydroxyurea, mycophenolate mofetil, azathioprine, oral retinoids, ciclosporin, or adalimumab were excluded from the study. Participants who reported that their sleep was severely disturbed when wearing the ABPM device were also excluded.

A complete physical examination was performed on all subjects, including measurement of height, weight, heart rate, and $\mathrm{BP}$. The BMI was calculated as weight in $\mathrm{kg} / \mathrm{height}$ in square meters for all subjects. Waist circumference, taken midway between the lowest rib and the iliac crest, and hip circumference, taken at the level of the greater trochanters, were measured to the nearest millimeter using a flexible tape.

Blood samples were collected following a 12-h overnight fast and analyzed by the hospital clinical laboratory. Fasting blood samples were obtained for glucose, lipids, high sensitivity C-reactive protein (hs-CRP), creatinine, and white blood cell count (WBC). Biochemical and hematological parameters were measured by an Olympus AU 600 autoanalyzer (Olympus Optical Co., Ltd., Schimatsu-Mishima, Japan) and Bayer Advia 120 Cell CBC Counter Hematologia autoanalyzer (Bayer Advia 120 CBC counter, NJ, USA). Hs-CRP was measured by the highsensitivity nephelometric method (Dade Behring, Marburg, Germany). Total cholesterol, triglycerides, and high-density lipoprotein cholesterol were analyzed enzymatically using a 
Hitachi 747 (Japan) analyzer. Low-density lipoprotein cholesterol was calculated using the Friedewald formula.

\section{Evaluation of patient disease activity}

The diagnosis of psoriasis vulgaris was based on dermatologist diagnosis and/or description of characteristic lesions. Disease duration ranged from 6 months to 35 years (mean range, $12.8 \pm 8.3$ ). The clinical severity was determined according to the Psoriasis Area and Severity Index (PASI) [21]. The PASI assesses 4 body regions: the head, trunk, upper extremities, and lower extremities. For each region, the surface area involved is graded from 0 to 6 and each of 3 parameters (erythema, thickness, and scaling of the plaques) is graded from 0 to 4 . The scores from the regions were summed to give a PASI score ranging from 0 to 72 . The Psoriasis Severity Index (PSI) was also used to evaluate clinical signs (erythema, thickness, and scaling) on a scale of 0 (absent) to 3 (severe), for a possible total score up to 3 [22]. Affected body surface area (BSA) was also evaluated. The Nail Psoriasis Severity Index (NAPSI) was used to quantify the degree of nail changes [23]. The NAPSI was assessed separately for each fingernail and toenail. It is a numeric, simple tool for evaluation of nail psoriasis. This scale was used to evaluate the severity of nail bed psoriasis and nail matrix psoriasis. Each nail was evaluated for the presence or absence of nail matrix disease (pitting, leukonychia, red spots in lunula, nail plate crumbling) and nail bed disease (oil drop salmon patch discoloration, onycholysis, nail bed hyperkeratosis, and splinter hemorrhage). The sum of the scores for all of the nails was the patient's NAPSI. Nail involvement was considered for patients with NAPSI score $\geq 1$. Table 1 summarizes the disease-specific characteristics of the patients.

\section{Office blood pressure measurement}

Office BP was measured from the brachial artery using a mercury sphygmomanometry (ERKA D-83646 Bad Tölz, Kallmeyer Medizintechnik GmbH \& Co. KG, Germany). An appropriate cuff size was chosen for each subject. Systolic and diastolic BPs were taken as the first and fifth phases of Korotkoff sounds. The office BPs were measured by trained medical personnel at admission during the physical examination and then on the following day before ABPM. After at least 5 min of sitting rest, $B P$ was measured 2 times with 1-minute intervals. The average of these measurements was used to determine office BP. The repeatability of BP measurements with a mercury sphygmomanometer was calculated by an intra-class correlation coefficient $(0.92 ; 95 \% \mathrm{Cl}: 0.90-0.94 ; p=0.001)$. If the readings differed by $5 \mathrm{mmHg}$, an extra reading was obtained. The average of these 3 readings was defined as office BP. None of the readings were dropped. Extra measurements were required for only 5 subjects. Two sphygmomanometric office BPs were taken by trained medical personnel (during the physical examination
Table 1. Disease specific characteristics of the patients with psoriasis vulgaris.

\begin{tabular}{|c|c|c|}
\hline Variable & \multicolumn{2}{|c|}{ Mean \pm SD } \\
\hline Mean age of onset (years) & $21.5 \pm 9.1$ & (range: 2-39) \\
\hline $\begin{array}{l}\text { Mean duration of disease } \\
\text { (years) }\end{array}$ & $13.0 \pm 8.4$ & (range: $0.5-35$ ) \\
\hline Mean PASI score & $2.9 \pm 3.7$ & (range: 0-23.4) \\
\hline Mean PSI score & $1.4 \pm 0.8$ & (range: $0-3$ ) \\
\hline Mean affected BSA (\%) & $4.6 \pm 10.3$ & (range: 0-90) \\
\hline Mean NAPSI score & $25.2 \pm 24.0$ & (range: 1-93) \\
\hline $\begin{array}{l}\% \text { of patients with nail } \\
\text { involvement }\end{array}$ & \multicolumn{2}{|c|}{$64.5(71 / 110)$} \\
\hline
\end{tabular}

SD - standart deviation; PASI - psoriasis area and severity Index; PSI - psoriasis severity Index; BSA - body surface area;

NAPSI - nail psoriasis severity Index.

and then on the following day before ABPM). The agreement analysis between devices was performed on the healthy subjects. The interclass correlation coefficient between a mercury sphygmomanometer and an ABPM device was calculated as 0.86 (95\% Cl: 0.82-0.90; $p=0.001)$.

\section{Ambulatory blood pressure monitoring}

Twenty-four-hour ABPM was carried out with a validated noninvasive automatic device (Tonoport V, PAR Medizintechnik $\mathrm{GmbH}$, Berlin, Germany) and the cuff of the device was fitted on the non-dominant arm. Patients were instructed to maintain the same daily routine and sleep patterns and to stop muscular activity (especially sports activity) and to keep their arms entirely still during BP measurements. The BP monitor was programmed to measure BP at intervals of 20 min during the daytime and $30 \mathrm{~min}$ at night. Each BP reading was edited by a computer and rejected if the systolic BP was less than $80 \mathrm{mmHg}$ or more than $250 \mathrm{mmHg}$ or if the diastolic BP was less than $40 \mathrm{mmHg}$ or more than $140 \mathrm{mmHg}$. Recordings for each subject were accepted if more than $80 \%$ of the raw data were valid. Average values were calculated for 2 periods of a whole day: a 5-h period between 1 AM and 6 AM (nighttime) and a 12-h period between 9 AM and 9 PM (daytime). Average daytime ABPM of less than $135 / 85 \mathrm{mmHg}$ and average nighttime ABPM of less than $120 / 70 \mathrm{mmHg}$ were considered as normotensive (Group 1) [11,24]. Patients with 24-h ambulatory BP above these limits but normal office BP were considered as masked hypertensive (Group 2) [25]. The percentage of decline in sleep BP was calculated as follows: decline in sleep SBP (\%) = (daytime average SBP - nighttime average SBP) $\times 100 /$ daytime average SBP. Non-dippers are defined as those who showed a reduction in BP of less than 
Table 2. Baseline characteristics and laboratory findings of the study population.

\begin{tabular}{|c|c|c|c|}
\hline Variable & Group $1(n=110)$ & Group $2(n=110)$ & $\mathbf{p}$ \\
\hline Age (year) & $34.7 \pm 6.3$ & $35.8 \pm 7.8$ & 0.23 \\
\hline Male gender (\%) & $56 / 110(51.1)$ & $56 / 110(51.1)$ & 1.00 \\
\hline Current smoker (\%) & $55 / 110(50.0)$ & $48 / 110(43.6)$ & 0.34 \\
\hline BMI $\left(\mathrm{kg} / \mathrm{m}^{2}\right)$ & $26.3 \pm 3.1$ & $25.7 \pm 2.2$ & 0.10 \\
\hline Waist circumference $(\mathrm{cm})$ & $95.9 \pm 10.5$ & $95.8 \pm 11.0$ & 0.97 \\
\hline Hip circumference (cm) & $100.4 \pm 8.1$ & $98.0 \pm 9.4$ & 0.09 \\
\hline Office Systolic BP (mmHg) & $114.7 \pm 11.6$ & $116.9 \pm 9.8$ & 0.14 \\
\hline Office Diastolic BP (mmHg) & $72.7 \pm 8.0$ & $73.5 \pm 8.7$ & 0.25 \\
\hline Office HR (beats per minute) & $75.2 \pm 9.5$ & $77.2 \pm 7.2$ & 0.09 \\
\hline Serum glucose (mg/dl) & $92.4 \pm 11.1$ & $91.1 \pm 9.1$ & 0.37 \\
\hline Serum total cholesterol (mg/dl) & $188.7 \pm 36.1$ & $188.3 \pm 31.8$ & 0.74 \\
\hline Serum LDL cholesterol (mg/dl) & $124.6 \pm 32.1$ & $119.5 \pm 25.4$ & 0.20 \\
\hline Serum HDL cholesterol (mg/dl) & $44.4 \pm 11.6$ & $44.8 \pm 11.5$ & 0.78 \\
\hline Serum triglycerides (mg/dl) & $136.3 \pm 81.2$ & $121.0 \pm 43.1$ & 0.09 \\
\hline
\end{tabular}

$\mathrm{BMI}$ - body mass index; BP - blood pressure; HR - heart rate; LDL - low-density lipoprotein; HDL - high-density lipoprotein.

$10 \%$ between the average daytime and nighttime SBPs. If the nighttime SBP decrease was $\geq 10 \%$, it was classified as dipper [24]. The average of BPs during the first $4 \mathrm{~h}$ after waking was defined as morning BP [26].

\section{Statistical analysis}

Statistical analysis was carried out using SPSS for Windows version 13.0 (SPSS, Chicago, IL). Categorical variables are presented as frequency and percent, and compared with the chisquared test. Normally distributed continuous variables are presented as mean \pm standard deviation, and compared with the independent samples t-test. Non-normally distributed continuous variables were presented as median and range, and compared with the Mann-Whitney $U$ test. The distribution of the variables was determined with the Kolmogorov-Smirnov $Z$ test for each study group. Those variables whose univariate associations trended toward statistically significance were considered for construction of the multivariate model. Stepwise backward logistic regression was performed to identify independent predictors of $\mathrm{MH}$. A $p$ value of $<0.05$ was considered statistically significant for all the tests.

\section{Results}

The main characteristics and laboratory findings of patients are summarized in Table 2. The study enrolled 110 psoriatic patients who had normal office BP (systolic 114.7 \pm 11.6 , diastolic $72.7 \pm 8.0 \mathrm{mmHg}$ ) and 110 normotensive subjects (systolic $116.9 \pm 9.8$, diastolic $73.5 \pm 8.7 \mathrm{mmHg}$ ). Both groups were similar in terms of age, sex, anthropometric measures such as $\mathrm{BMI}$, waist, and hip circumference, and laboratory measures of lipid profile and fasting glucose.

All of the patients successfully (capturing $\geq 80 \%$ valid readings) completed 24-h ABPM (total 54 measurements, 12 of them during the night between $1 \mathrm{AM}$ and $6 \mathrm{AM}$ ). The average ABPM session duration was $21.4 \mathrm{~h}$. The average percentage of valid readings obtained was $87 \%$. Fifty-four perfect readings were obtained in 79 patients ( $73.1 \%$ of the study population). An even worse number was 46/54 measurements (85\% success). The nighttime and 24-h average BP values (SBP, DBP, and $M A B P$ ) and daytime SBP were significantly higher in patients with psoriasis vulgaris compared to the control subjects (Table 3). The decline in BP during the night was blunted in psoriatic patients (for systolic BP, $9.2 \pm 4.7$ vs. $8.4 \pm 3.8 \mathrm{mmHg}$, $p=0.41)$ and patients with non-dipper BP profile were common in Group 1 (34/75, 45.3\% in Group 1 and 21/33, 63.6\% in Group 2, $p=0.08$ ). The average MABP values at early morning were also elevated in psoriatic patients $(p<0.01)$.

The characteristics of participants with and without $\mathrm{MH}$ are shown in Table 4. The prevalence of $\mathrm{MH}$ was $24.1 \%$ (53/220). $\mathrm{MH}$ was more common in patients with psoriasis vulgaris compared to control subjects $(35 / 110,31.8 \%$ vs. $18 / 110,16.4 \%$, 
Table 3. Ambulatory blood pressure monitoring results of the patients (group 1) and control subjects (group 2).

\begin{tabular}{|c|c|c|c|c|}
\hline \multicolumn{2}{|c|}{ Parameter } & Group $1(n=110)$ & Group $2(n=110)$ & $\mathbf{p}$ \\
\hline \multirow{4}{*}{ 24-hour } & $\mathrm{SBP}(\mathrm{mmHg})$ & $120.1 \pm 9.1$ & $117.8 \pm 6.0$ & 0.02 \\
\hline & $\mathrm{DBP}(\mathrm{mmHg})$ & $76.0 \pm 7.2$ & $74.0 \pm 6.5$ & 0.03 \\
\hline & MABP $(\mathrm{mmHg})$ & $90.7 \pm 7.8$ & $87.9 \pm 5.9$ & $<0.01$ \\
\hline & HR (bpm) & $75.8 \pm 8.1$ & $76.2 \pm 6.3$ & 0.72 \\
\hline \multirow{3}{*}{ Daytime } & $\mathrm{SBP}(\mathrm{mmHg})$ & $124.3 \pm 9.3$ & $121.9 \pm 6.7$ & 0.03 \\
\hline & $\mathrm{DBP}(\mathrm{mmHg})$ & $79.3 \pm 7.5$ & $78.1 \pm 7.5$ & 0.24 \\
\hline & MABP $(\mathrm{mmHg})$ & $93.4 \pm 8.5$ & $91.3 \pm 7.5$ & 0.05 \\
\hline \multirow{3}{*}{ Night-time } & $\mathrm{SBP}(\mathrm{mmHg})$ & $113.7 \pm 9.1$ & $109.4 \pm 6.0$ & $<0.01$ \\
\hline & $\mathrm{DBP}(\mathrm{mmHg})$ & $69.8 \pm 7.5$ & $66.5 \pm 5.2$ & $<0.01$ \\
\hline & MABP $(\mathrm{mmHg})$ & $85.4 \pm 7.9$ & $79.5 \pm 5.7$ & $<0.01$ \\
\hline \multirow{2}{*}{ Ä Day-Night } & $\mathrm{SBP}(\mathrm{mmHg})$ & $9.0 \pm 4.4$ & $10.5 \pm 4.2$ & 0.01 \\
\hline & $\mathrm{DBP}(\mathrm{mmHg})$ & $11.1 \pm 5.9$ & $14.0 \pm 6.4$ & $<0.01$ \\
\hline \multicolumn{2}{|c|}{ Non-dipper (\%) } & $56 / 110(51.0)$ & $38 / 110(34.5)$ & 0.01 \\
\hline \multirow{3}{*}{$\begin{array}{c}\text { Early morning } \\
\text { average }\end{array}$} & $\mathrm{SBP}(\mathrm{mmHg})$ & $111.7 \pm 11.0$ & $109.8 \pm 12.8$ & 0.31 \\
\hline & DBP $(\mathrm{mmHg})$ & $68.7 \pm 9.4$ & $66.2 \pm 12.8$ & 0.17 \\
\hline & MABP $(\mathrm{mmHg})$ & $82.7 \pm 9.7$ & $77.5 \pm 9.3$ & $<0.01$ \\
\hline
\end{tabular}

SBP - systolic blood pressure; DBP - diastolic blood pressure; $\Delta$ Day-Night - difference between day and night average BP values.

p<0.01) (Figure 1). Male sex, smoking, being overweight and having central obesity (higher BMI, waist and hip circumferences), and dyslipidemia (higher triglyceride and lower HDL cholesterol levels) were associated with MH (Table 4). These variables were entered into a binary logistic regression analysis for the detection of the predictors of $\mathrm{MH}$, which revealed male sex and $\mathrm{BMI}$ as independent predictors of $\mathrm{MH}$ in the whole study population (Table 5).

Similar to the results of the whole study population, $\mathrm{MH}$ was associated with male sex (28/35 vs. 28/75, $p<0.01)$, smoking $(23 / 35$ vs. $32 / 75, p=0.04)$, and obesity-related anthropometric measures such as BMI $(27.5 \pm 2.6$ vs. $25.8 \pm 3.1, p<0.01)$ and waist circumference $(102.1 \pm 10.1$ vs. $94.0 \pm 9.9 \mathrm{~cm}, p<0.01)$ in patients with psoriasis vulgaris. $\mathrm{MH}$ was significantly associated with severity of the disease. Disease-specific indexes (PASI, BSA, and $\mathrm{PSI}$ ) were significantly higher in patients with $\mathrm{MH}(p<0.01)$. To define predictors of $\mathrm{MH}$ in patients with psoriasis vulgaris, clinical characteristics and disease-specific indexes found to be significantly associated with $\mathrm{MH}$ were entered into the binary logistic regression with backward stepwise methods (sex, smoking, BMI, waist circumference, PASI, BSA, and PSI). Male sex, waist circumference, and BSA were found to be the independent predictors of $\mathrm{MH}$ in patients with psoriasis (Table 6).

\section{Discussion}

The primary finding of the present study was that MH was considerably more frequent in patients with psoriasis vulgaris. The 
Table 4. Clinical characteristics of the participants with or without masked hypertension.

\begin{tabular}{|c|c|c|c|}
\hline Variable & No masked hypertension ( $n=167$ ) & Masked hypertension ( $n=53$ ) & $\mathbf{p}$ \\
\hline Age (year) & $35.1 \pm 7.3$ & $35.7 \pm 6.7$ & 0.58 \\
\hline Male gender (\%) & $72(43.1)$ & $40(75.4)$ & $<0.01$ \\
\hline Current smoker (\%) & $69(41.3)$ & $34(64.1)$ & $<0.01$ \\
\hline BMI $\left(\mathrm{kg} / \mathrm{m}^{2}\right)$ & $25.6 \pm 2.6$ & $27.5 \pm 2.3$ & $<0.01$ \\
\hline Waist circumference $(\mathrm{cm})$ & $94.5 \pm 10.6$ & $101.4 \pm 8.9$ & $<0.01$ \\
\hline Hip circumference (cm) & $98.7 \pm 8.9$ & $102.5 \pm 6.8$ & 0.02 \\
\hline Serum glucose (mg/dl) & $91.5 \pm 10.6$ & $92.6 \pm 8.4$ & 0.50 \\
\hline Serum LDL cholesterol (mg/dl) & $120.3 \pm 28.4$ & $127.6 \pm 30.3$ & 0.11 \\
\hline Serum HDL cholesterol (mg/dl) & $45.5 \pm 11.9$ & $41.8 \pm 9.8$ & 0.05 \\
\hline Serum triglycerides (mg/dl) & $124.5 \pm 59.2$ & $148.1 \pm 80.3$ & 0.01 \\
\hline $\begin{array}{l}\text { Non-dipping nocturnal BP } \\
\text { pattern (\%) }\end{array}$ & $68(40.7)$ & $28(52.8)$ & 0.09 \\
\hline
\end{tabular}

BMI - body mass index; LDL - low-density lipoprotein; HDL - high-density lipoprotein; BP - blood pressure.

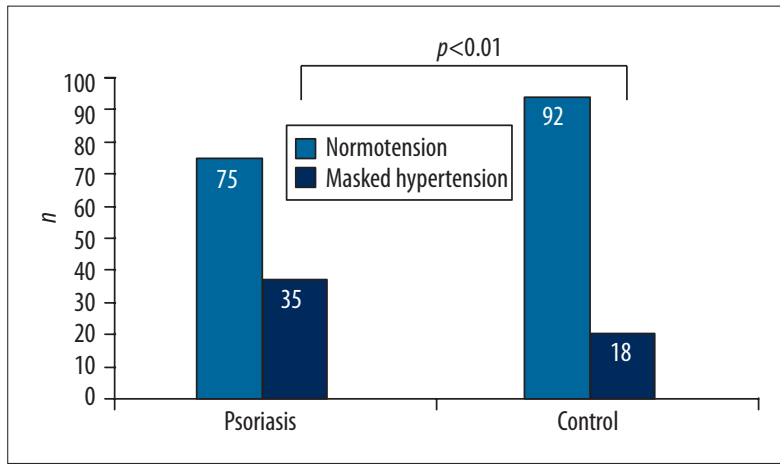

Figure 1. Prevalence of masked hypertension in both groups.

MH-related factors were identified as male sex, waist circumference, and severity of the disease assessed by BSA. Patients with these characteristics should be monitored more closely for the development of essential hypertension.

The relationship between psoriasis vulgaris and diseases increasing cardiovascular morbidity and mortality (e.g., metabolic syndrome, obesity, essential hypertension, dyslipidemia, and type 2 diabetes mellitus) has been demonstrated [10]. Particularly, essential hypertension is quite common in psoriatic patients $[9,10,27]$. Moreover, patients with psoriasis vulgaris who have hypertension are more likely to have more hypertension that is more difficult to control and require a greater number of anti-hypertensive medications than non-psoriatic, hypertensive patients [28]. Subclinical atherosclerosis induced by chronic systemic inflammation and increased oxidative stress in psoriasis might cause endothelial dysfunction and promote structural and functional changes of the arterial wall, resulting in high BP $[29,30]$. Furthermore, derangement in autonomic cardiovascular regulation, enhanced activity of the renin-angiotensin system, and insulin resistance might be responsible for hypertension development in these patients [31-33]. Vascular dysfunction associated with hypertension (eg, increased arterial stiffness and carotid intima media thickness) were demonstrated in asymptomatic psoriatic patients $[34,35]$.

The current consensus about comorbidities in patients with psoriasis vulgaris is that BP should be checked annually in patients receiving local treatment and every 6 months in patients on systemic treatment, to detect and treat hypertension [10]. Although conventional office BP measurement with a sphygmomanometer remains the reference method for diagnosis of hypertension, it is frequently variable, inaccurate, and misleading [36]. Measuring BP with ABPM instead provides a BP profile throughout the whole $24-\mathrm{h}$ period more accurately and can identify patients with $\mathrm{MH}$ or blunted $\mathrm{BP}$ reduction at night who are at greater risk for hypertension development, target organ damage, and cardiovascular morbidity and mortality [25]. Recently, we have reported that the non-dipping nocturnal BP pattern is more common in normotensive psoriatic patients compared to normal individuals [27]. Similar to results of the present study, half of the patients $(51.0 \%)$ had non-dipper BP.

Defined as normal office BP with elevated ambulatory or home $\mathrm{BP}, \mathrm{MH}$ has been drawing attention recently $[37,38]$. Several prospective studies have demonstrated that $\mathrm{MH}$ was associated with hypertensive end organ damage such as left ventricular hypertrophy, impaired renal function, carotid atherosclerosis, and a poor cardiovascular prognosis [12-14,39]. It 
Table 5. A binary logistic regression model for the associations of clinical variables with masked hypertension in the whole study population $(n=220)$.

\begin{tabular}{|lccc|}
\hline \multicolumn{1}{c}{ Variables } & OR & $\mathbf{9 5 \%} \mathbf{~ C l}$ & $\mathbf{P}$ \\
\hline Male gender & 1.11 & $1.18-3.90$ & 0.01 \\
\hline Smoking & 1.66 & $1.00-2.76$ & 0.05 \\
\hline BMI $\left(\mathrm{kg} / \mathrm{m}^{2}\right)$ & 1.38 & $1.02-1.87$ & 0.04 \\
\hline Waist circumference $(\mathrm{cm})$ & 1.35 & $0.54-3.41$ & 0.52 \\
\hline Hip circumference $(\mathrm{cm})$ & 0.73 & $0.29-1.87$ & 0.51 \\
\hline HDL cholesterol $(\mathrm{mg} / \mathrm{dl})$ & 1.02 & $0.97-1.08$ & 0.43 \\
\hline Triglycerides $(\mathrm{mg} / \mathrm{dl})$ & 1.00 & $0.99-1.01$ & 0.99 \\
\hline Presence of psoriasis $(\%)$ & 1.11 & $0.65-1.90$ & 0.70 \\
\hline
\end{tabular}

$\mathrm{OR}$ - odds ratio; $\mathrm{Cl}$ - confidence interval; $\mathrm{BMI}$ - body mass index.

Table 6. Independent predictors of masked hypertension in patients with psoriasis vulgaris $(n=110)$.

\begin{tabular}{lccc|}
\multicolumn{1}{c}{ Variables } & OR & $\mathbf{9 5 \%} \mathbf{~ C l}$ & $\mathbf{P}$ \\
\hline Male gender & 9.00 & $2.06-39.24$ & $<0.01$ \\
\hline Waist circumference $(\mathrm{cm})$ & 1.08 & $1.02-1.15$ & 0.01 \\
\hline BSA $(\%)$ & 1.35 & $1.06-1.70$ & 0.01 \\
\hline
\end{tabular}

Dependent variable: Presence of masked hypertension, Nagelkerke $\mathrm{R}^{2}=0.53$. Gender, smoking, BMI, waist circumference, PASI, BSA, and $\mathrm{PSI}$ were entered into the logistic regression model. OR - odds ratio; $\mathrm{Cl}$ - confidence interval; $\mathrm{BMI}$ - body mass index;

PASI - psoriasis area and severity index; BSA - body surface area.

has shown that left ventricular mass and carotid wall thickness were greater in subjects with $\mathrm{MH}$ compared to normotensives, and were similar to those with essential hypertension [15]. Some of the factors leading to $\mathrm{MH}$ were previously described as older age, male sex, smoking, alcohol consumption, contraceptive use in women, and sedentary lifestyle [20]. Also, increases in obesity-related anthropometric indices such as waist circumference, $\mathrm{BMI}$, or waist-to-hip ratio were also associated with $\mathrm{MH}$, especially in men [40]. Based on our review of the current literature, this is the first study to demonstrate increased prevalence of $\mathrm{MH}$ in patients with psoriasis. Results of the present study confirmed the previous data, as $\mathrm{MH}$ was more frequent in male smokers with central obesity. Although it has been reported that the prevalence of $\mathrm{MH}$ was higher in elderly subjects, large population-based studies and clinic samples did not confirm the association of age with $\mathrm{MH}[15,19,41,42]$. Patients in this study were younger (mean age, 34.8 years) than participants of the previous studies and older patients were not included into the study in order to prevent the effects of aging and age-related disorders; therefore, it was not possible to demonstrate any relation between age and $\mathrm{MH}$.
It is quite reasonable to expect such a relationship between $\mathrm{MH}$ and severity of the disease. In order to assess activity and severity of psoriasis, a number of indexes (PASI, PSI, BSA, and NAPSI) were used. Most of the patients (102/108, 94.4\%) in this study had mild chronic plaque-type psoriasis (PASI <7) (Table 1). Among these parameters, only BSA was related with $\mathrm{MH}(p=0.01, \exp (\beta)=1.54,95 \% \mathrm{Cl}: 1.24-1.91$ and $p=0.01$, $\exp (\beta)=1.41,95 \% \mathrm{Cl}: 1.16-1.71$, respectively). These findings confirm that hypertension is even more frequent in patients with mild disease [10]. The prevalence of $\mathrm{MH}$ in patients with psoriasis vulgaris was $30.5 \%$ in this study, which is consistent with the previous data from the meta-analysis of 22 studies examining the association between hypertension and psoriasis that revealed the prevalence of hypertension ranged from $15.1 \%$ to $32 \%$ in patients with mild psoriasis, and from $19 \%$ to $40.3 \%$ in those with moderate to severe psoriasis [10].

\section{Study limitations}

The small number of subjects was the most important limitation of this study. The other limitation was absence of BP follow-up in both groups. Alcohol consumption and the frequency 
of leisure physical activity of the subjects were not measured Also, we did not evaluate patients for target organ damages such as left ventricular hypertrophy, microalbuminuria, renal dysfunction, and carotid artery wall thickness. The ABPM was taken at several different postures including supine position during sleep and standing posture during daily physical activity, which could affect the accuracy of BP measurement. Moreover, we do not have data before and after initiation of therapy to see whether this treatment affects circadian BP pattern. For this reasons, large-scale and long-term follow-up prospective studies are required to establish the predictive value of $\mathrm{MH}$ for adverse cardiovascular events in patients with psoriasis vulgaris.

\section{Conclusions}

In conclusion, our study revealed that $\mathrm{MH}$ is highly prevalent in normotensive patients with psoriasis vulgaris, even if they are young and non-obese. It may be speculated that increased incidence of $\mathrm{MH}$ in psoriatic patients could predispose to target organ damage and adverse cardiovascular outcomes. Further prospective studies are warranted not only to verify this relationship but also to elucidate the exact mechanisms. These findings confirm that psoriatic patients, even those who were

\section{References:}

1. Schön MP, Boehncke WH: Psoriasis. N Engl J Med, 2005; 352: 1899-912

2. Acikbas I, Sanlı B, Tepeli E et al: Vitamin D receptor gene polymorphisms and haplotypes (Apa I, Bsm I, Fok I, Taq I) in Turkish psoriasis patients. Med Sci Monit, 2012; 18(11): CR661-66

3. Prodanovich S, Kirsner RS, Kravetz JD et al: Association of psoriasis with coronary artery, cerebrovascular, and peripheral vascular diseases and mortality. Arch Dermatol, 2009; 145: 700-3

4. Rosa DJ, Machado RF, Matias FA et al: Influence of severity of the cutaneous manifestations and age on the prevalence of several cardiovascular risk factors in patients with psoriasis. J Eur Acad Dermatol Venereol, 2012; 26: $348-53$

5. Markuszeski L, Bissinger A, Janusz I et al: Heart rate and arrhythmia in patients with psoriasis vulgaris. Arch Med Res, 2007; 38: 64-69

6. Ahlehoff $\mathrm{O}$, Gislason $\mathrm{GH}$, Jørgensen $\mathrm{CH}$ et al: Psoriasis and risk of atrial fibrillation and ischaemic stroke: a Danish Nationwide Cohort Study. Eur Heart J, 2012; 33: 2054-64

7. Krzesiński P, Gielerak GG, Kowal J): A "patient-tailored" treatment of hypertension with use of impedance cardiography: A randomized, prospective and controlled trial. Med Sci Monit, 2013; 19: 242-50

8. Sommer DM, Jenisch S, Suchan M et al: Increased prevalence of the metabolic syndrome in patients with moderate to severe psoriasis. Arch Dermatol Res, 2006; 298: 321-28

9. Zindancı I, Albayrak O, Kavala $M$ et al: Prevalence of metabolic syndrome in patients with psoriasis. Scientific World Journal, 2012; 2012: 312463

10. Daudén E, Castañeda S, Suárez C et al: [Integrated approach to comorbidity in patients with psoriasis]. Actas Dermosifiliogr, 2012; 103(Suppl.1): 1-64

11. Pickering TG, Hall JE, Appel LJ et al: Recommendations for Blood Pressure Measurement in Humans and Experimental Animals: Part 1: Blood Pressure Measurement in Humans: A Statement for Professional and Public Education of the American Heart Association Council on High Blood Pressure Research. Circulation, 2005; 111: 697-716

12. Bjorklund $\mathrm{K}$, Lind L, Zethelius $\mathrm{B}$ et al: Isolated ambulatory hypertension predicts cardiovascular morbidity in elderly men. Circulation, 2003; 107 1297-302 normotensive and with mild disease, had increased cardiovascular risk. Physicians caring for patients with psoriasis vulgaris should not only treat skin lesions but also screen them for different types of hypertension such as MH. Use of an ABPM device could represent the hidden part of the iceberg and it should be ordered as a part of suggested screening for hypertension. These patients should be monitored more closely and be evaluated for end-organ damage such as microalbuminuria, left ventricular hypertrophy, and carotid artery thickness. Lifestyle modification including low-salt diet, weight reduction, exercise, and smoking cessation should be recommended, and medical treatment should be ordered immediately if necessary. It should be noted that younger patients profit most when preventive strategies are implemented early.

\section{Declaration of interest}

The authors report no conflicts of interest. The authors alone are responsible for the content and writing of the paper.

\section{Acknowledgements}

We received no financial sponsorship, funding, or sources of support in the form of grants, equipment, or drugs.

13. Bobrie G, Chatellier G, Genes N et al: Cardiovascular prognosis of 'masked hypertension' detected by blood pressure self-measurement in elderly treated hypertensive patients. JAMA, 2004; 291: 1342-49

14. Ohkubo T, Kikuya M, Metoki $\mathrm{H}$ et al: Prognosis of 'masked' hypertension and 'white-coat' hypertension detected by $24-\mathrm{h}$ ambulatory blood pressure monitoring 10-year follow-up from the Ohasama study. J Am Coll Cardiol, 2005; 46: 508-15

15. Liu JE, Roman MJ, Pini R et al: Cardiac and arterial target organ damage in adults with elevated ambulatory and normal office blood pressure. Ann Intern Med, 1999; 131: 564-72

16. Sega R, Trocino G, Lanzarotti A et al: Alterations of cardiac structure in patients with isolated office, ambulatory, or home hypertension: data from the general population (Pressione Arteriose Monitorate E Loro Associazioni [PAMELA] Study). Circulation, 2001; 104: 1385-92

17. Imai Y, Tsuji I, Nagai K et al: Ambulatory blood pressure monitoring in evaluating the prevalence of hypertension in adults in Ohasama, a rural Japanese community. Hypertens Res, 1996; 19: 207-12

18. Palatini $P$, Winnicki $M$, Santonastaso $M$ et al: Prevalence and clinical significance of isolated ambulatory hypertension in young subjects screened for stage I hypertension. Hypertension, 2004; 44: 170-74

19. Selenta C, Hogan BE, Linden W: How often do office blood pressure measurements fail to identify true hypertension? An exploration of white-coat normotension. Arch Fam Med, 2000; 9: 533-40

20. Palatini P: Masked hypertension: how can the condition be detected? Blood Press Monit, 2004; 9: 297-99

21. Louden BA, Pearce DJ, Lang W, Feldman SR: A Simplified Psoriasis Area Severity Index (SPASI) for rating psoriasis severity in clinic patients. Dermatol Online J, 2004; 10: 7

22. Amornpinyokeit N, Asawanonda P: 8-Methoxypsoralen cream plus targeted narrowband ultraviolet $\mathrm{B}$ for psoriasis. Photodermatol Photoimmunol Photomed, 2006; 22: 285-89

23. Rich $P$, Scher RK: Nail Psoriasis Severity Index: a useful tool for evalua-tion of nail psoriasis. J Am Acad Dermatol, 2003; 49: 206-12

24. Madin K, Iqbal P: Twenty four hour ambulatory blood pressure monitoring: a new tool for determining cardiovascular prognosis. Postgrad Med J, 2006; 82: 548-51 
25. O'Brien E, Asmar R, Beilin L et al: Practice guidelines of the European Society of Hypertension for clinic, ambulatory and self blood pressure measurement. J Hypertens, 2005; 23: 697-701

26. Soylu A, Yazici M, Duzenli MA et al: Relation between abnormalities in circadian blood pressure rhythm and target organ damage in normotensives. Circ J, 2009; 73: 899-904

27. Bacaksiz A, Akif Vatankulu M, Sonmez O et al: Non-dipping nocturnal blood pressure in psoriasis vulgaris. Wien Klin Wochenschr, 2012; 124(23-24): 822-29

28. Armstrong AW, Lin SW, Chambers CJ et al: Psoriasis and hypertension severity: results from a case-control study. PLoS One, 2011; 6: e18227

29. Flammer AJ, Ruschitzka F: Psoriasis and atherosclerosis: two plaques, one syndrome? Eur Heart J, 2012; 33: 1989-91

30. Cymerys M, Bogdański P, Pupek-Musialik D et al: Influence of hypertension, obesity and nicotine abuse on quantitative and qualitative changes in acute-phase proteins in patients with essential hypertension. Med Sci Monit, 2012; 18(5): CR330-36

31. Halıgür BD, Cicek D, Bulut S, Berilgen MS: The investigation of autonomic functions in patients with psoriasis. Int J Dermatol, 2012; 51: 557-63

32. Ena $\mathrm{P}$, Madeddu $\mathrm{P}$, Glorioso $\mathrm{N}$ et al: High prevalence of cardiovascular diseases and enhanced activity of the renin-angiotensin system in psoriatic patients. Acta Cardiol, 1985; 40: 199-205

33. Boehncke WH, Boehncke S: Cardiovascular morbidity in psoriasis: epidemiology, pathomechanisms, and clinical consequences. G Ital Dermatol Venereol, 2008; 143: 307-513
34. Enany B, El Zohiery AK, Elhilaly R, Badr T: Carotid intima-media thickness and serum leptin in psoriasis. Herz, 2012; 37: 527-33

35. Gisondi P, Fantin F, Del Giglio M et al: Chronic plaque psoriasis is associated with increased arterial stiffness. Dermatology, 2009; 218: 110-13

36. Pierdomenico SD, Cuccurullo F: Ambulatory blood pressure monitoring in type 2 diabetes and metabolic syndrome: a review. Blood Press Monit, 2010; 15: 1-7

37. Pickering TG, Davidson K, Gerin W, Schwartz JE: Masked hypertension. Hypertension, 2002; 40: 795-96

38. Longo D, Dorigatti F, Paratini P: Masked hypertension in adults. Blood Press Monit, 2005; 10: 307-10

39. Kawano Y, Horio T, Matayoshi T, Kamide K: Masked Hypertension: Subtypes and Target Organ Damage. Clin Exp Hypertens, 2008; 30: 289-96

40. Asayama K, Sato A, Ohkubo T et al: The association between masked hy pertension and waist circumference as an obesity-related anthropometric index for metabolic syndrome: the Ohasama study. Hypertens Res, 2009 32: $438-43$

41. Rasmussen SL, Torp-Pedersen C, Borch-Johnsen K, Ibsen H: Normal values for ambulatory blood pressure and differences between casual blood pressure and ambulatory blood pressure: results from a Danish population survey. J Hypertens, 1998; 16: 1415-24

42. Mancia G, Sega R, Bravi C et al: Ambulatory blood pressure normality: results from the PAMELA study. J Hypertens, 1995; 13: 1377-90 